\title{
Sex Disparity in Satisfaction and Loyalty Towards Urban Rail Transit: A Survey of Light Rail Transit (LRT) Passengers in Kuala Lumpur, Malaysia
}

\author{
Ahmad Nazrul Hakimi Ibrahim ${ }^{1}$, Muhamad Nazri Borhan ${ }^{1 *}$ \\ ${ }^{1}$ Department of Civil Engineering, Faculty of Engineering and Built Environment, \\ Universiti Kebangsaan Malaysia, 43600 UKM Bangi, Selangor, MALAYSIA \\ *Corresponding Author
}

DOI: https://doi.org/10.30880/ijie.2021.13.03.027

Received 05 January 2021; Accepted 13 May 2021; Available online 10 June 2021

\begin{abstract}
The aim of this study is to explore the effect of sex disparity on passenger satisfaction and loyalty to the light rail transit (LRT) services in Kuala Lumpur, Malaysia. A total of 417 responses from a self-administrated questionnaire were analyzed using non-parametric tests, namely Mann-Whitney U test and Spearman's correlation test. Based on the Mann-Whitney U test, results showed a significant difference between male and female LRT passengers in terms of their satisfaction and loyalty. In addition, the Spearman's correlation test proved a significant and positive relationship between passengers' sex, satisfaction and loyalty. Finally, future suggestions were made based on the findings reported in this study.
\end{abstract}

Keywords: urban rail transit, light rail transit, satisfaction, loyalty, gender disparity, user perception

\section{Introduction}

Urbanization is a complex process experienced by many cities around the globe. This phenomenon results in rural migration and even suburban concentration in cities, causing rapid population growth in the city area especially in developed countries [1]. For example, in European countries, about $80 \%$ of the population live in urban area due to this phenomenon [2]. Malaysia as one of the most developing countries in Southeast Asia is not an exception in the urbanization phenomenon and has received a huge number of migration from rural area and/or suburban area to urban area. In 2020, the urbanization rate in Malaysia was forecasted to be about 70\%. Kuala Lumpur, one of the Malaysian Federal Territories, is the major contributor to the rate of urbanization in Malaysia. Statistics reported that the population density in Kuala Lumpur is very high with 6891 people/ $\mathrm{km}^{2}$ [3]. According to Maruthaveeran \& Bosh [4], and Mohd Noor et al. [3], the population of Kuala Lumpur in 2016 was 1.76 million, and was projected to have a population of 2.2 million in 2020 .

The higher population in city area has caused urban agglomeration which leads to high demand of transportation for mobility. As reported in the vast transportation literature, public transportation is a vital element in the global effort to promote the use of sustainable transportation [5]-[10]. In Kuala Lumpur, for instance, the government and authorities have made a huge effort to provide high quality public transportation in order to reduce dependency on private transportation and promote the use of sustainable transportation. Today, advanced public transportation systems such as railway have been introduced in Kuala Lumpur as the future backbone of transportation network that provides an efficient, reliable, affordable, and eco-friendly travel alternative [11]. However, the great effort put in by the government and authorities is not in line with the public response in terms of public transportation usage, especially railway. Statistics have shown that the use of private transportation in Kuala Lumpur is still dominant with the reported 
number of trips of 6 million (83\%) compared to public transportation with 1.24 million (17\%) in 2010 [5], [12]. This issue is prevalent in other parts of the world too where low number of public transportation usage has been observed as compared to private transportation [6], [13]. Masirin et al. [14] and Ibrahim et al. [6] reported that railway ridership in Kuala Lumpur is still low even though the government has made huge investments to encourage the use of railway since the past few decades. Moreover, the issue of lower railway usage has been reported as a serious concern in the transportation literature for the Asian region [15].

Previous research in the transportation domain have highlighted that the lack of enthusiasm to use railway is due to the failure of service providers to provide the level of quality services expected by the passengers [6], [16], [17]. In other words, passengers are not satisfied with the services provided. In the context of public transportation, passenger satisfaction was defined as an overall evaluation based on the total experience with services over time [18]. On the other hand, passenger loyalty is the tendency to continue using the provided service and the willingness to recommend the service to others [19].

According to Shen et al. [20], high level of service quality of public transportation increases passenger satisfaction, which in turn ensures passenger retention and attracts potential passengers to use the services. Today, in line with further development of the public transportation system, the expectation towards railway systems is high. In addition, competition with other types of public transports such as bus, taxi, and informal ones (such as Grab) as well as private transports also influence the satisfaction and loyalty level among passengers [18].

Saturation in the transportation market and increasing competition from other types of public and private transportation have raised the significance of passenger satisfaction and loyalty, and importance of maintaining continuity and stability. Knowing passengers better and providing high quality services in accordance to their preferences are vital ways to increase railway ridership. For this reason, railway service providers especially, should analyze the characteristics of passengers better and should not neglect the effects of demographic factors such as sex from consideration. Thus, using the LRT services of Kuala Lumpur, Malaysia as a case study, this research was conducted to investigate the effect of sex disparity among LRT passengers towards the satisfaction and loyalty to the services. In addition, this research explored the effect of passenger satisfaction towards their loyalty to LRT services.

\section{Methodology}

The aim of this study is to explore the effect of sex disparity on passenger satisfaction and loyalty to the urban rail transit. Thus, the Kuala Lumpur light rail transit (LRT) was chosen as a case study in this paper. The Kuala Lumpur LRT system consists of three lines, namely the Ampang Line, the Sri Petaling Line and the Kelana Jaya Line which spans $18 \mathrm{~km}$ (18 stations), $45.1 \mathrm{~km}$ (29 stations) and $46.4 \mathrm{~km}$ (37 stations) respectively.

\subsection{Questionnaire Design}

The instrument used in this study was adopted and modified from those used in previous studies [20], [21] and is presented in Appendix A; the instrument has been back translated into Malay. Prior to the final data collection, the questionnaire was administered on 50 randomly selected respondents in Bandar Baru Bangi, Selangor as a pilot test. The results of reliability analysis of the pilot study are presented in Table 1. The items were measured using a fivepoint Likert scale, ranging from $1=$ Strongly dissatisfied/disagree to $5=$ Strongly satisfied/agree. A higher score shows a higher level of interest in a particular measure.

Table 1 - Construct items and reliability analysis of the instruments

\begin{tabular}{|c|c|c|c|}
\hline Construct & $\begin{array}{l}\text { Adopted } \\
\text { from: }\end{array}$ & $\begin{array}{l}\text { Number of } \\
\text { Items }\end{array}$ & 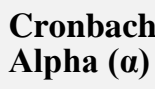 \\
\hline Passenger Satisfaction & {$[20],[21]$} & 4 & 0.870 \\
\hline Passenger loyalty & {$[20],[21]$} & 7 & 0.872 \\
\hline
\end{tabular}

\subsection{Sample Size and Data Collection}

The questionnaires were distributed to 500 LRT passengers on the basis of convenience sampling technique from 20 September 2019 to 10 December 2019. Of the returned questionnaires, 417 of them were considered for further analysis while 83 were eliminated due to "straight liners" and respond with missing value. "Straight liners" are the respondents who consistently select the maximum, minimum or center point on the scales. According to Hair et al. [22], straight lining should be removed form data set. In addition, the unanswered question (missing data) more than $10 \%$ were removed from this study as suggested by Jakobsen et al. [23].

\subsection{Data Analysis and Tools}


The 417 data were analyzed using IBM SPSS Statistics version 24.0. Prior to the data analysis process, the data were encoded and made suitable for the analysis. Then, the normality test was applied on the data. The data analysis was done using descriptive test and non-parametric tests which are Mann-Whitney U test and Spearman's correlation test. The authors decided to use non-parametric test in this study as the data did not show a normal distribution as recommended by Uca et al. [24].

\section{Research Hypotheses}

The hypotheses were proposed in this study to investigate the relationship among the independent variable and dependent variables as follows:

- Hypothesis 1: There is a significant relationship between the sex of passengers and the satisfaction towards the LRT services.

- Hypothesis 2: There is a significant relationship between the sex of passengers and the loyalty towards the LRT services.

\section{Results and Discussion}

\subsection{Descriptive Analysis for Passenger Satisfaction and Loyalty}

This study was conducted by analyzing 417 valid responses from Kuala Lumpur LRT passengers. Of the total, the majority respondents were male with 212 (50.84\%) while the female respondents were 205 (49.16\%). Following that, the descriptive results such as mean and standard deviation value for passengers' levels of satisfaction and loyalty has displayed in Fig. 1. For passenger satisfaction, the range of mean value for each item is between 3.487 and 3.621 with the highest mean for item PS1. In addition, the range of standard deviation value for passenger satisfaction is between 0.969 and 1.029. In terms of passenger loyalty, the range of mean value for each item is between 3.405 and 3.707 , with the highest mean was reported for item PL3. The standard deviation value for passenger loyalty was ranging between 0.961 and 1.070 .

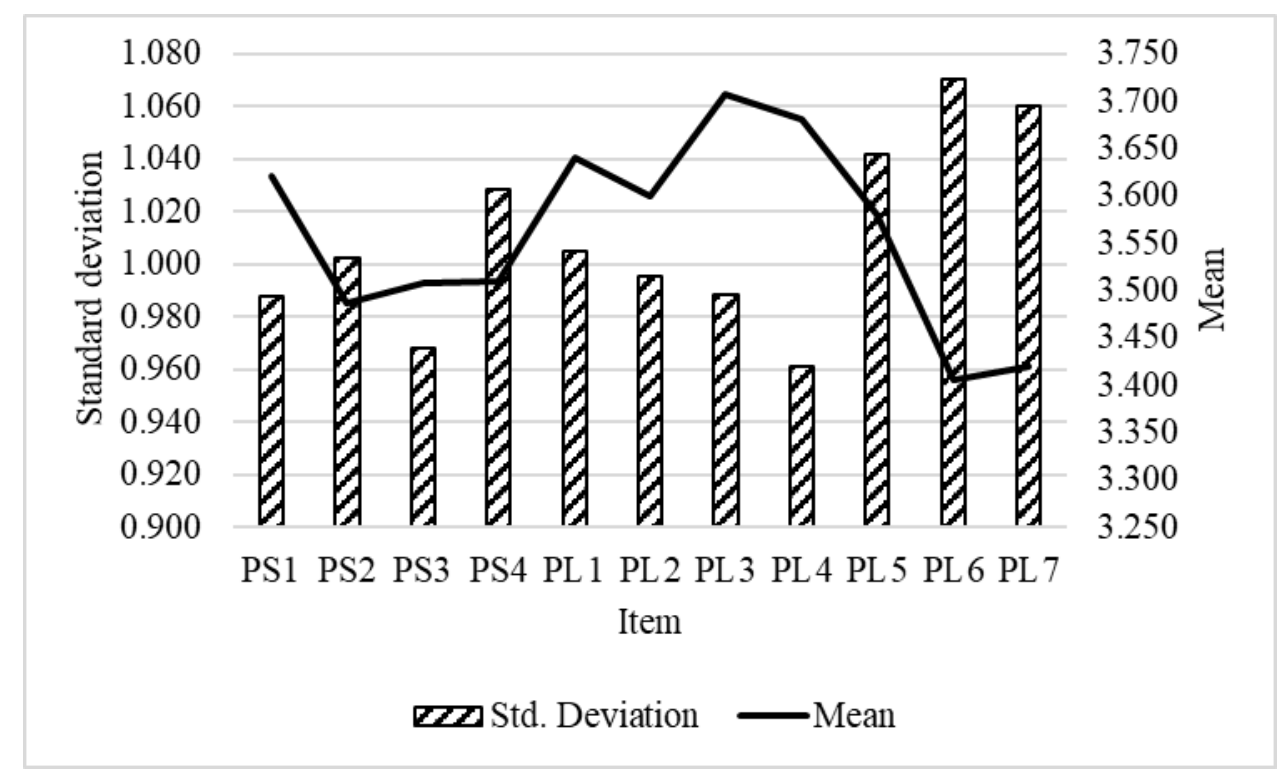

Fig. 1 - The mean and standard deviation of passenger satisfaction and loyalty

\subsection{The Effect of Sex Disparity on Passenger Satisfaction and Loyalty}

Based on the normality analysis using Shapiro-Wilk test, the significant level for dependent variables, namely satisfaction and loyalty was $0.00(\rho<0.05)$ for both variables. This indicated that the data were not normally distributed. According to Uca et al. [24], the non-parametric test, Mann-Whitney U test is appropriate to investigate the differences between two independent groups for non-normally distributed data sets.

Table 2 summarizes the comparison results between two independents groups (male and female) on the levels of satisfaction and loyalty. The results showed that the male and female passengers had a statistically significant difference $(\rho=0.003)$ in the context of satisfaction level towards the LRT services. Thus, Hypothesis 1 is supported, and the null hypothesis is rejected. In summary, a significant difference between satisfaction level among male and female passengers was found. In terms of passenger loyalty, Table 2 shows a significant value of $0.005(\rho<0.05)$. Therefore, Hypothesis 2 is supported, and the null hypothesis is rejected. The results in this study indicate a significant 
difference between two groups of independent variables (male and female) towards their loyalty to the LRT services. The findings in this study have supported a previous work by Jiang \& Zhang [25] which indicated that male and female passengers differ significantly in terms of several service qualities based on their assessment of user experience at the Melbourne airport. However, opposite results were reported in other studies [24], [26]. For instance, Jiang \& Zhang [26] indicated that demographic factors such as sex, nationality, and education level did not have a significant effect on satisfaction level in the case of China's airlines market.

Table 2 - Results of Mann-Whitney U test

\begin{tabular}{ccccc}
\hline $\begin{array}{c}\text { Dependent } \\
\text { variable }\end{array}$ & $\begin{array}{c}\text { Independent } \\
\text { variable (Sex) }\end{array}$ & N & Z-value & $\begin{array}{c}\text { o-value } \\
\text { (Asymp. sig.) }\end{array}$ \\
\hline Satisfaction & Male & 212 & -2.962 & 0.003 \\
& Female & 205 & & 0.005 \\
Loyalty & Male & 212 & -2.779 & \\
\hline
\end{tabular}

\subsection{The Relationship Between Passengers' Sex, Satisfaction and Loyalty}

The correlation of passengers' sex, satisfaction and their loyalty towards the LRT services in Kuala Lumpur was investigated in this study via Spearman's correlation test, also known as non-parametric correlation test. Table 3 shows the correlation results between three variables based on the opinions from 417 Kuala Lumpur LRT passengers. Based on Table 3, a Spearman's rho correlation test showed that the relationship between passenger sex and their satisfaction and loyalty are statistically significant with correlation coefficient of $0.145(\rho=0.003)$ and $0.136(\rho=0.005)$ respectively. In addition, the relationship between passenger sex and satisfaction and, passenger sex and loyalty showed a weak correlation coefficient $(\mathrm{r}= \pm 0.3)$.

On the other hand, a significant and positive correlation $(r=0.785, \rho=0.000)$ between two variables, namely satisfaction and loyalty were observed. In other words, the satisfaction level of passengers has strong relationship ( $\mathrm{r}>$ 0.7 ) between the loyalty of passengers towards the service. In this study, the satisfied passengers may have a higher tendency to be loyal by reusing the LRT services in the future and recommending them to others. This finding is similar to other previous works in the transportation domain [19], [27]-[31].

In line with that, LRT service providers should invest more resources and focus more on physical policies such as providing a safe environment at the LRT station and in the train, a reasonable fare, a wide network coverage, punctual and high frequency services, sufficient parking space at the stations, and convenience in the train and at the station. These serve to provide high-quality services that meet passengers' expectations, leading to their satisfaction after using the services as well as enhancing loyalty among current passengers and attracting new ones.

Table 3 - The relationship between passengers' sex, satisfaction and loyalty

\begin{tabular}{cccc}
\hline & Sex & Satisfaction & Loyalty \\
\hline Sex & 1 & & \\
Satisfaction & $0.145^{* *}$ & 1 & 1 \\
Loyalty & $0.136^{* *}$ & $0.785^{* *}$ & 1 \\
\hline
\end{tabular}

Note: **. Correlation is significant at the 0.01 level

\section{Conclusion}

The current study had established the effect of sex disparity on passenger satisfaction and loyalty towards the Kuala Lumpur LRT services. This study also investigated the correlation between passenger sex, passenger satisfaction and loyalty. In summary, based on the non-parametric tests, a significant difference was found among male and female passengers in terms of their satisfaction and loyalty to the services provided. In addition, this study proved a significant and positive relationship between three variables, which is sex, satisfaction and loyalty. Finally, the present study provided beneficial information that can help key players in the LRT industry such as service providers, authorities, policy makers, and researchers to formulate effective strategies. This is to increase satisfaction towards the services provided and increase LRT ridership especially in Kuala Lumpur, Malaysia.

\section{Acknowledgement}


This research was funded by Universiti Kebangsaan Malaysia (UKM) under the project code GUP-2019-015. The authors also wish to thank the passengers of Kuala Lumpur LRT who have participated in this study.

\section{Appendix A: Measurement}

\begin{tabular}{cll}
\hline Construct & Items \\
\hline \multirow{2}{*}{$\begin{array}{c}\text { Passenger } \\
\text { satisfaction }\end{array}$} & PS2 & $\begin{array}{l}\text { Overall satisfaction towards the quality of LRT service } \\
\text { My perception towards the service provided is beyond my expectation } \\
\text { My perception of the comprehensiveness of the services provided is beyond my } \\
\text { expectation }\end{array}$ \\
& PS4 & I think I have benefited from using the LRT service \\
\hline & PL1 & I will continue to use the LRT service in the future \\
PLassenger loyalty & I am willing to give more effort to use the LRT service \\
& PL4 & I would recommend the LRT service to others \\
& PL5 & I am proud to tell others I have used the LRT service \\
PL6 & I use the LRT service on a regular basis \\
PL7 & I have been using the LRT service to travel over the years
\end{tabular}

\section{References}

[1] Murakami A., Medrial Zain A., Takeuchi K., Tsunekawa A. \& Yokota S. (2005). Trends in urbanization and patterns of land use in the Asian mega cities Jakarta, Bangkok, and Metro Manila. Landscape and Urban Planning, 70, 251-259

[2] Borhan M. N., Ibrahim,A. N. H., Syamsunur D. \& Rahmat R. A. (2019). Why public bus is a less attractive mode of transport: A case study of Putrajaya, Malaysia. Periodica Polytechnica Transportation Engineering, 47, 82-90

[3] Mohd Noor N., Rosni N. A., Hashim M. \& Abdullah A. (2018). Developing land use geospatial indices (LUGI) for sprawl measurement in alpha cities: Case study of Kuala Lumpur, Malaysia. Cities, 82, 127-140

[4] Maruthaveeran S., \& Van den Bosh C. K. (2015). Fear of crime in urban parks - What the residents of Kuala Lumpur have to say? Urban Forestry and Urban Greening, 14, 702-713

[5] Kwan S. C., Sutan, R. \& Hashim J. H. (2018). Trip characteristics as the determinants of intention to shift to rail transport among private motor vehicle users in Kuala Lumpur, Malaysia. Sustainable Cities and Society, 36, 319326

[6] Ibrahim A. N. H., Borhan M. N., Md. Yusoff N. I. \& Ismail A. (2020). Rail-based public transport service quality and user satisfaction - A literature review. Promet-Traffic \& Transportation, 32, 423-435

[7] Morton C., Caulfield B. \& Anable J. (2016). Customer perceptions of quality of service in public transport: Evidence for bus transit in Scotland. Case Studies on Transport Policy, 4, 199-207

[8] Ibrahim A. N. H., Borhan M. N., Zakaria N. A. \& Zainal S. K. (2019). Effectiveness of commuter rail service toward passenger's satisfaction: A case study from Kuala Lumpur, Malaysia. International Journal of Engineering and Technology, 8, 50-55

[9] Borhan M. N., Ibrahim A. N. H. \& Miskeen M. A. A. (2019). Extending the theory of planned behaviour to predict the intention to take the new high-speed rail for intercity travel in Libya: Assessment of the influence of novelty seeking, trust and external influence. Transportation Research Part A: Policy and Practice, 130, 373-384

[10] Borhan M. N., Ibrahim A. N. H., Miskeen M. A. A., Rahmat R. A. O. K. \& Alhodairi A. M. (2017). Predicting car drivers' intention to use low cost airlines for intercity travel in Libya. Journal of Air Transport Management, 65, 88-98

[11] Kwan S. C., Tainio M., Woodcock J., Sutan R. \& Hashim J. H. (2017). The carbon savings and health co-benefits from the introduction of mass rapid transit system in Greater Kuala Lumpur, Malaysia. Journal of Transport and Health, 6, 187-200

[12] Chiu C. O., Karim M. R. \& Yusoff S. (2014). Mode choice between private and public transport in Klang Valley, Malaysia. The Scientific World Journal, 2014, 1-9

[13] van Lierop D., Badami M. G. \& El-Geneidy A. M. (2018). What influences satisfaction and loyalty in public transport? A review of the literature. Transport Reviews, 38, 52-72

[14] Mohd Masirin M. I., Salin A. M., Zainorabidin A., Martin D. \& Samsuddin N. (2017). Review on Malaysian rail transit operation and management system: Issues and solution in integration. IOP Conference Series: Materials Science and Engineering, 226, 1-7 
[15] Mohamad Zulkifli S. N. A., Kadar Hamsa A. A., Noor N. M. \& Ibrahim M. (2017). Evaluation of land use density, diversity and ridership of rail based public transportation system. Transportation Research Procedia, 25, 5266-5281

[16] Belwal R. (2017). Public transportation in Oman: A strategic analysis. Advances in Transportation Studies, 42 , 99-116

[17] Chowdhury S. (2016). Users' willingness to ride an integrated public-transport service: A literature review. Transport Policy, 48, 183-195

[18] Ibrahim A. N. H. \& Borhan M. N. (2020). The interrelationship between perceived quality, perceived value and user satisfaction towards behavioral intention in public transportation: A review of the evidence. International Journal on Advanced Science Engineering and Information Technology, 10, 2048-2056

[19] Chou J. S., \& Kim C. (2009). A structural equation analysis of the QSL relationship with passenger riding experience on high speed rail: An empirical study of Taiwan and Korea. Expert Systems with Applications, 36, 6945-6955

[20] Shen W., Xiao W. \& Wang X. (2016). Passenger satisfaction evaluation model for urban rail transit: A structural equation modeling based on partial least squares. Transport Policy, 46, 20-31

[21] Irtema H. I. M., Ismail A., Borhan M. N., Das A. M. \& Alshetwi A. B. Z. (2018). Case study of the behavioural intentions of public transportation passengers in Kuala Lumpur. Case Studies on Transport Policy, 6, 462-474

[22] Hair J. F., Hult G. T. M., Ringle C. M. \& Sarstedt M. (2014). A primer on partial least squares structural equation modeling (PLS-SEM). SAGE Publications

[23] Jakobsen J. C., Gluud C., Wetterslev J. \& Winkel P. (2017). When and how should multiple imputation be used for handling missing data in randomised clinical trials - A practical guide with flowcharts. BMC Medical Research Methodology, 17, 162

[24] Uca S., Altintas V., Tuzunkan D. \& Toanoglou M. (2017). A study on the effects of demographic factors on hotel selection process. International Journal of Tourism Sciences, 17, 231-246

[25] Jiang H. \& Zhang Y. (2016). An assessment of passenger experience at Melbourne Airport. Journal of Air Transport Management, 54, 88-92

[26] Jiang H. \& Zhang Y. (2016). An investigation of service quality, customer satisfaction and loyalty in China's airline market. Journal of Air Transport Management, 57, 80-88

[27] Hussain R., Al Nasser A. \& Hussain Y. K. (2015). Service quality and customer satisfaction of a UAE-based airline: An empirical investigation. Journal of Air Transport Management, 42, 167-175

[28] Hu H. H. (Sunny), Kandampully J. \& Juwaheer T. D. (2009). Relationships and impacts of service quality, perceived value, customer satisfaction, and image: An empirical study. The Service Industries Journal, 29, 111125

[29] van Lierop D. \& El-Geneidy A. (2016). Enjoying loyalty: The relationship between service quality, customer satisfaction, and behavioral intentions in public transit. Research in Transportation Economics, 59, 50-59

[30] Ibrahim A. N. H., Borhan M. N. \& Rahmat R. A. O. K. (2020). Understanding users' intention to use park-andride facilities in Malaysia: The role of trust as a novel construct in the theory of planned behaviour. Sustainability (Switzerland), 12, 2484

[31] Ibrahim A. N. H., Borhan M. N., Md. Yusoff N. I., Ismail A., Mat Yazid M. R., Mhd Yunin N. A., Sotaro Y. (2021). Gender and age do matter: Exploring the effect of passengers' gender and age on the perception of light rail transit service quality in Kuala Lumpur, Malaysia. Sustainability (Switzerland), 13, 990 